\title{
UNDERSTANDING THE CONTAINMENT OF PUBLIC SPACES: UPGRADING PUBLIC DOMAIN
}

\author{
ROBERT BARELKOWSKI \\ West-Pomeranian University of Technology Szczecin.
}

\begin{abstract}
Designing public spaces usually responds to social expectations and provides more rich urban environment able to accommodate various human activities. It is very important for health, well-being, and perceived quality of life of local community members. Urban design, even if purely intuitive and composition oriented may still produce attractive results, but ultimate impacts will not be seen until its implementation into physical use. Therefore the introduction of analytic and decision-supporting mechanisms seem to be justified.

In this paper an approach focused on qualities and typologies confronted with multiple functions of open public spaces is considered. It attempts to answer questions concerning connection between qualitative and quantitative aspects of urban environment. Within this connection parametric understanding supports the expert knowledge of designer. Multiple functions affect the efficiency of the geometry of open spaces and in turn the ability to sustain social attractiveness and usefulness of these areas. The paper will discuss problems of urban design from the perspective of intervening and designing public spaces in peripheral municipal zones in an efficient way. It proposes framework, its application, and shows specific key elements to be included in order to acquire these improvement oriented goals.

Keywords: FAST, public open spaces, sustainability, urban design analysis
\end{abstract}

\section{INTRODUCTION}

The power of urban space seems to be too complex to grasp. Cities expand and deteriorate at the same time in different places. Economic growth sometimes precedes economic downfall and costs of timely success are too high to be endured. Economic growth is also accompanied by urbanization frenzy, which affects the development of various areas in a different way. While some areas are carefully planned, particularly those treated as strategic or socially significant, many other estates are designed and executed with pure or dominating aspect of financial calculation in mind. This kind of orientation distorts proportions between various urban functions, particularly when it comes to the deficit of public spaces other than streets and routes.

In this article I intend to focus on the perspective and the role of public spaces in minor, more common or less strategic estates. It's aim is to examine the justification of introduction of public squares in small scale urban projects as well as to expose relationship between the qualities of urban space and typology as well as capacity of these spaces.

\section{THE RATIONALE FOR OPEN URBAN SPACES}

Dynamic growth of cities worldwide is very often associated with untamed, spontaneous expansion or urbanized areas at the expense of either rural areas or other previously unconverted land. This process affects empty, borderline space between cities and accompanying settlements, but it also has its impact on the fringes of villages usually surrounding the city. This peripheral growth becomes the greatest challenge and the strongest potential for vitality of the city as its most weakening point raising multiple risks [1,2]. Simultaneously, reorganization of internal parts of the city results in densification, consumption of emptied or vacant areas, most often in more organized manner due to overall supervision of municipal 
authorities. Following the processes of accumulation of people, built structures, individual or social activities are various phenomena resulting in diverse and rich patterns of urban life supported or impeded by physical forms of the city. There is a fundamental connection between urban space in its material aspect, and its meaning, program, and use, a cultural imprint related to social organization, cultural traits as well as the sum of personal experiences and representations which serve as part of identity of every citizen. Stephan Schmidt and Jeremy Nemeth see this relationship as uncontested and continually valid, relevant [3]. An example of a content which is inherent in space, yet being artificial creation of society, is laws and their application, another example can be seen as containment - the ability to accommodate human activities. This issue can be linked to John Searle's concept of social reality which is constructed of two domains - brute facts representing physical aspects of urban space and institutional facts representing semiologic aspects [4]. Both domains are inseparable, while the processes of socialization inherently saturate space with meanings and all objects are socially attributed (regardless of their usability). This dualism, however, is beneficial and explanatory for reasoning, exposing also another kind of spatial distinction objective and subjective. Searle's "brute facts" seen here as physical objects provide material tissue of the city and correspond to objects: buildings, tectonics of various surfaces, urban furniture, sculptures and installations, "institutional facts" translates to how people move through spaces, how they use them, how they interpret them, sometimes in a dynamic way, altering their purpose. As Ali Madanipour notices the physical component of urban space is objective, while the symbolic is contextual [5] - and spatial context is very significant to assure distinction of space and its appropriation for the needs of inhabitants, for building the identity. Madanipour's consideration of public spaces turns our attention towards implicit meanings of power, control, but also belonging and opportunity (or opportunities) to fulfill or satisfy expectations, requirements.

Somehow this duality of urban space establishes an interpretative framework for what constitutes urban structure, dimensions recognized also as spatial dimensions. In the 1980s. Stanley Benn and Gerald Gaus proposed the tension between the private and the public as the main force organizing social life, manifesting in agencies using interests (of various shareholders or participants) to assure or gain access to particular other agencies [6]. At the same time these components act as agents of continuity maintaining mutual interconnections, but they also permeate autonomy and self-organization. Public spaces are main conveyors of connectivity, thus accessibility, but particular public spaces acquire additional meanings by becoming navigation points [7], identity generators, among others. What is distinguishable, local features, but also local culture and specific unique configurations and interactions are responsible for establishing selective accessibility, with various layers of significance dependent on connection of the recipient with this space, what implies also the ability to read spatial context. And even if contemporary urban activities are vastly represented in virtual world, still the physicality of the city seems to be necessary to satisfy the everyday bodily experience of a man. This tangible connection provides permanence, impossible to be matched by its possible simulacrum in the domain of information [8].

The city requires these arteries and these nodes of public spaces to uphold its life-sustaining processes. The above-mentioned specific spaces like squares, plazas, however, have more significance than mere connecting channels. Despite the fact that contemporary activities are processed outside of public spaces (in specialized buildings or even outside of physical space), these arenas still retain importance due to their functional flexibility and can still be seen as remedy against urban fragmentation, just like they were intended to work in 19th century. Also arenas - larger spaces having ability to accommodate more people in one place 
for longer period - help in building the sense of community without breaching private spaces, intimate zones of personal use. This countermeasure against sociospatial fragmentation of the city provides spaces of opportunity to meet a stranger, to enjoy public events, to socialize, to rest and relax. Robert Cowley reviews various sources on the public and finds that regardless of the impact these spaces possess on the quality of the city, their positive influence cannot be underestimated [9]: behind Kurt Iveson, he describes already mentioned duality of spatial nature which is unveiled in topographic and performative roles open spaces often have. Regardless of the discourse on contemporary condition of public spaces, the concept of its privatization, main and multiple functions described by Lewis Mumford [10] or Spiro Kostof [11] in regards of historic evolution, are still valid, and briefly reported by many researchers - transportation, social cohesion, integration (socialization), safety, recreation, reinforcement of economic ties, urban ventilation and provision of green areas (green pockets as reservoirs for fauna and flora), microclimate regulators etc. [12, 13].

It is justified to see the public squares and plazas as special areas of public interest and activities, and their existence as desirable regardless of validity of many interpretations, also those critical, which aptly point out deficiencies of contemporary public spaces. Issues of mobility, dynamic changes, virtuality clash with eco-tendencies of reduction of emissions through use of public transportation or total elimination by providing all necessary functions within walking distance, with autonomization, and demands of the real. While some of issues raised by Michael Sorkin on the apparent crisis of public spaces remain valid [14], mostly due to enormous advantage of the market and the dictate of economy resulting in shortsighted decisions related to land value, but also by different social patterns, social stratifications, incorporation of some crucial functions of open public spaces by private buildings - commercial centers, airports, railway stations, and by the disconnection between design aesthetic qualities and expected social qualities [15], physical open public spaces are still relevant and indispensable to create and maintain spatial spine of the city.

Urban designers and planners are nowadays discouraged to incorporate squares and plazas in their designs, partially because of the pressure of market forces and calculations focused on quick gains through commercialization, and partially (and paradoxically) by the proliferation of social participation in which members of local communities have more say than in the past, yet they lack knowledge and information necessary to make well-grounded, conscious decision. In peripheral areas of cities, in areas with lower density of development, public squares are perceived as excessive, particularly when designed on private grounds. The latter cases often lead to frequent omissions, rejections of public spaces which are not dedicated to transportation purposes. Even parameters of some roads or streets - if exceed legal minimal size - are contested. This tendency is reinforced by intuition-driven design in which public spaces are designed according to individual (architect's) preferences. Aspects of social sustainability become contradictory, because social acceptance not always accompanies planned spaces for social cohesion. So, is it worth to re-introduce public spaces and this way grant certain urban qualities as well as acquire tangible results?

\section{FROM "WHY?" TO "HOW?"}

Very often open public spaces are created as a network of interconnected nodes, providing dispersed system of spaces of cumulation linked through streets which play the role of spaces of transfer. The importance of these public spaces is seemingly increased towards the most dense, downtown areas of cities, which partially is the result of historical development exposing the respect to how cities grow and acquire their identity, and partially caused by tacit professional knowledge, loosely related to objective parameters and performance of the city 
[16]. Their presence in design schemes reflects the response to particular explicit or implicit needs. It is important to clarify that parametric approach - connecting the emergence of public spaces to the number of inhabitants, to programming of functions to be contained in these spaces - is not completely new. In post-war modern urban design approaches factor-driven urban design was certainly common approach for architects, however it was restricted to several basic pieces of information - usually connecting number of people inhabiting area under design with expected surface of public squares to be included in the scheme. Functions were usually restricted to recreation, extended to hosting public events only in pre-selected few sites - the decision on putting particular program was related to administrative organization of the city instead of real, contextual requirements of the site.

Only recently this trend has been reversed and urban factors are seen in more broad context as both examples of and modifying agents for positive and more profoundly understood transformation of urban environment [17]. With some exceptions, like e.g. Housing Quality Indicators (HQI) introduced in a systemic way in order to precede design and implementation [18], most of multi-criteria assessments act retrospectively, and appear more often as sciencebased research than fully implemented design procedures integrated into planning-designing cycle. Even in HQI system there is significant gap between qualitative and quantitative approach to project information. This is well exposed in how logic values of this system (fulfilling certain conditions or yes/no criteria) are correlated to rather discreet than continuous parameters of the project. It may be seen as necessary consequence of inability to accommodate infinite multiplicity of unique spatial configurations, but in fact it doesn't say much about how conformity to practical usage conditions is met [19].

Physical composition of urban space is a result of urban design, which in turn can be focused on containment of multiple functional profiles, relevant typologies, and socializing as well as aesthetic qualities, among others. The lack of multi-criteria approach preceding design decisions is a deficiency of planning and designing which can be mitigated. The remedy must acknowledge complex social interactions, their primary impact on public areas of the city, going far beyond purely functionalist approach, stemming from basic human need to integrate, to communicate, to congregate, namely to socialize, and it reaches furthermore - to public or social health related to both sensory change, leisure and recreation, it improves economic background of urban tissue. And as Susan Drucker and Gary Gumpert notice, these complex processes can be contained in places as trivial as cafeterias, with all their various and apparent modes of use [20]. This is also related to the preservation of spontaneity in selforganization of forms of social interactions by members of local community, thus resulting in necessity to create sites of potential instead of sites of defined character and program [21]. General agreement between researchers becomes however unsolved in terms of application of particular principles in urban design practice. While it would be irrational to claim that typological-parametric pre-design analysis is fundamental solution for establishing appropriate framework and acquire high (or higher) quality of public spaces, it definitely may significantly improve giving answers to some crucial aspects of design. Therefore remaining part of this work is dedicated to explain not why, or what, but how problem of parametric comparative analysis may be exploited to understand estimated results - ex ante.

\section{METHOD AND ITS APPLICATION: FROM TYPOLOGY TO PARAMETERS}

The proposed framework for establishing the solutions for urban design of open public spaces assumes the combination of programmatic definitions influencing dependent formulas which are both related to program with typology and demographics of particular area. Naturally 
there are multiple other issues related to criteria influencing the solution, however the concept behind the framework (typological-parametric) concentrates on particular elements of design process which allow for easy elimination of design errors.

Elements of FAST are used herein in order to determine the capacity of development area [22], which primarily disclose prognosed demographic profile and development of the estate in time. Also, FAST similarly to other methods or sustainability principles, acknowledges the influence of surroundings, particularly issues strongly linked to how and why public spaces work - walking distances, continuity of urban connections, visibilities (related to safety), and orientation, namely a clarity of spatial scheme.

Qualities of urban spaces are connected to functions. One of possible interpretations translating functions into respective qualities is presented by Vahid Bigdeli Rad and Ibrahim Bin Ngah, who establish comfort, leisure (described as relaxation), active and passive occupation, discovery, beauty, sociability, and security, or in brief version inviting character, security, desirability, and functionality [23]. Farzad Soltanian and Atefeh Mohammadi in their research for Salavatabad recognize similar set of attributes: comfort (and image - related to identity), sociability, activity, and accessibility [24]. While review of multiple research efforts shows compatible patterns of qualities, it also reveals nuances and differences, sometimes quite significant, proving that the area of quality definition is blurred and hardly can be seen as commonly agreed upon as stable set of references.

Typologies are related to qualities and directly allow to absorb different functions. Open public spaces can have multiple functions. Their purpose should be carefully programed depending on spatial context, spatial connections or relationships. Function-driven or process-driven parameters of public spaces can be, therefore, determined according to series of various formulas, upon recognition of available vectors of movement and joint impact of transfer volumes along with the way they may be compacted or condensed. Formulas allow for establishing minimal dimensions for particular type of use. E.g. may be green stripe of land, which is intended to assure bike route, sidewalk, designed row of trees, and green belt for compacted public fitness site (one elongated row of pieces of equipment). It requires to adopt the first selection, it is related to typology - linear, sequential, concentric, or multinodal. Let's pick linear typology - it restricts relevant position of subsequent substripes in a stipulated order.

$$
\mathrm{D}_{\mathrm{Amin}}=\mathrm{d}_{\mathrm{B}}+\mathrm{d}_{\mathrm{S}}+\left(\mathrm{d}_{\mathrm{T}}+2 * \mathrm{~b}_{\mathrm{T}}\right)+\left(\mathrm{d}_{\mathrm{G}}+2 * \mathrm{~b}_{\mathrm{G}}\right) .
$$

One can assume that the first substripe is greening, then bike route, next sidewalk, finally space to accommodate fitness site - the $D_{A}$ will be the width (or depth) of stripe, $d_{B}$ the width of bike route, $\mathrm{d}_{\mathrm{S}}$ width of sidewalk, $\mathrm{d}_{\mathrm{T}}$ width of treeline with $\mathrm{b}_{\mathrm{T}}$ buffer, and $\mathrm{d}_{\mathrm{G}}$ width of green substripe dedicated to fitness site, forced by the minimum dimension of the largest piece of equipment from the series of outdoor equipment, also with $b_{G}$ buffers.

The series of relevant and applicable formulas sensible for local context and patterns of use allow to understand the minimal size and optimal range of spaces. Location and number of potential users generate estimated pedestrian flow, spaces of personal comfort affect direct perception [25].

Five distinctive functions have been determined for open public spaces in this research: integration, recreation, sports, accommodation, and connection. The integration reflects capability of particular space to provide place for socialization, for the organization of public events or spontaneous (occasional) gatherings. The recreation offers buffer areas, green belts, and similar spaces. Sports activities can be contained in practically the same 

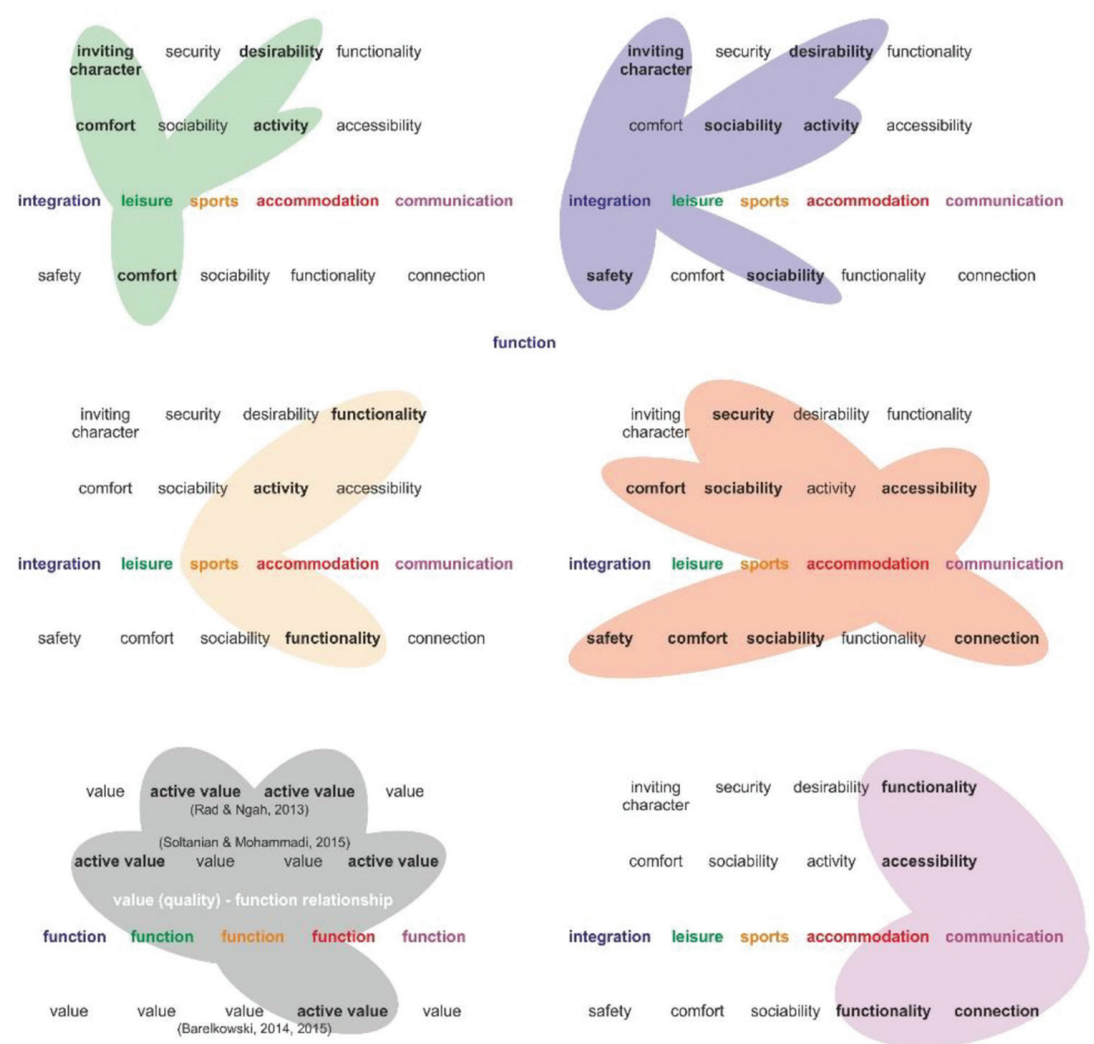

Figure 1: Connection between values (qualities) and functions. Auth.: RB, 2018.

areas as recreation with the provision that parameters will allow to locate particular playfields. Accommodation reflects the ability of urban space to allow for containment of individual activities performed outdoors. Connection determines communication between various locations.

The acknowledgement of various roles of urban spaces have been hierarchized and prioritized, stipulating integrative role as primary, recreation and sports as secondary, and accumulative as well as connection-related as tertiary. It reflects the importance of socializing, then the significance of human welfare in which health and living conditions are crucial. Connectivity and accumulation are less important providing redundancy to system of streets and roads used by the community. The resultant value returns amount of square meters $\left[\mathrm{m}^{2}\right]$ of open urban spaces designed per one person for estimated number of inhabitants of particular area.

Four different development areas have four distinct conditions and at the same time four different requirements for the creation of public spaces (Fig. 2). Four different estates in the peripheral zone of Poznan agglomeration require varied approach - Rokietnica Golecinska (A1), Napachanie Tarnowska (A2), Mrowino Kolejowa (A3) and Rokietnica Dzialkowa (A4). The first and the last area are situated within more dense, continuous urban tissue, while remaining two are remote, yet connected to other already urbanized settlements. 

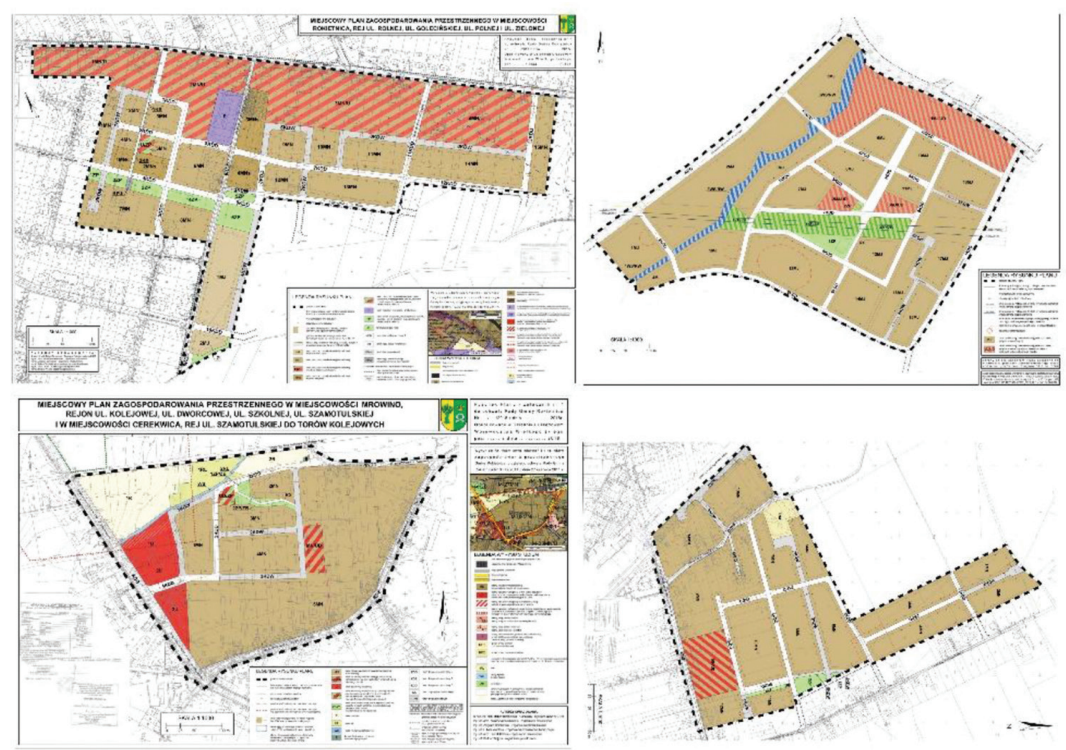

Figure 2: Four different cases: upper left - A1, upper right - A2, lower left - A3, lower right - A4. Auth.: RB, 2018.

Table 1: Basic data related to analyzed estates.

\begin{tabular}{lllll}
\hline Area identification & $\begin{array}{l}\text { Open public } \\
\text { space [ha] }\end{array}$ & $\begin{array}{l}\text { No of inhabitants } \\
\text { (estimated) }\end{array}$ & $\begin{array}{l}\text { Factor } \\
\text { Ppa[m2]/1 pers. }\end{array}$ & 100Ppa/ $\mathrm{PP}$ \\
\hline Rokietnica Golecinska & 0,7641 & 659 & $\mathbf{1 1 , 6 0 1 6}$ & $\mathbf{3 , 7 2}$ \\
Napachanie Tarnowska & 1,8281 & 825 & $\mathbf{2 2 , 1 5 0 4}$ & $\mathbf{6 , 2 1}$ \\
Mrowino Kolejowa & 0,5535 & 419 & $\mathbf{1 3 , 2 1 6 5}$ & $\mathbf{3 , 1 9}$ \\
Rokietnica Działkowa & 0,3329 & 671 & $\mathbf{4 , 9 6 5 0}$ & $\mathbf{1 , 6 4}$ \\
\hline
\end{tabular}

In table 1. raw, basic data is provided to illustrate unrelated, purely statistic image of four areas. Theoretically A2 (Napachanie) has the highest factor indicating over $22 \mathrm{sqm}$ of open public spaces available for inhabitants, while Rokietnica Golecinska has second lowest number from this set. However this image doesn't tell much about real usefulness and multiple functionality of public spaces as well as their ability to efficiently contain various functions due to typology and size. To reflect these phenomena formulas, which were exemplified by formula (1), serve the purpose of processing the data and anchor parameters in their functional and localized context. It is also related to weighted potential use by identified groups of inhabitants, regarding accessibility and proximity of public areas.

\section{RESULTS}

Herein the functional diversification represented by five profiles is exposing function dependent efficiency which corresponds to how in real life people can use spaces adjacent to their homes in every day life and in case of holding public events there. Spaces are analyzed 
according to their ability to contain particular profiles (integration, leisure, sports, accommodation, communication), and areas of efficiency (respectively Ppi, Ppr, Pps, Ppm and Ppk) are compared to total public space area (Ppa). Higher ratio exposes high compactness of multiplicity of functions, while lower exposes specialization and uniqueness of use. Profiles are weighted according to either diagnosed expectations of community being the result of public inquiry or according to multi-criteria assessment (MCA) used within FAST methodology or similar. It is important to notice that not only real values of efficient public spaces are significantly lower than raw categorization suggests, but also weighted assessment leads to appropriately adjusted image of efficiency of particular spatial program in different areas (Fig. 3).

The overall multi-functional efficiency acknowledging the typological aspect of urban design is measured between values 0 and 1, with 0 as defunct, values above 0 as low potential efficiency, and value approximating or equal to 1 depicting high to ultimate efficiency. These values (efficiencies) include the acknowledgement of contextual relations - which are necessary to indicate that not all functions in particular location have priority even if there is enough space to contain extensive area dedicated to that profile. As a result, the analysis and in this case the comparison show that even moderate planning for public spaces can have strong effects, while large open public areas don't necessarily produce socially consumable results. It is well seen in final results of parametric analysis in which location in Napachanie (A2) despite having the highest ratio of public space sqm per person has the lowest efficiency due to location related limitations, returning value of 0,2694. On the other hand relatively small estate in Rokietnica Dzialkowa (A4) has the lowest ratio, but careful planning for open spaces allowed for high efficiency accommodation of multiple roles and good accessibility giving the value of 0,5887 with only 4,97 sqm per person (Fig. 4).

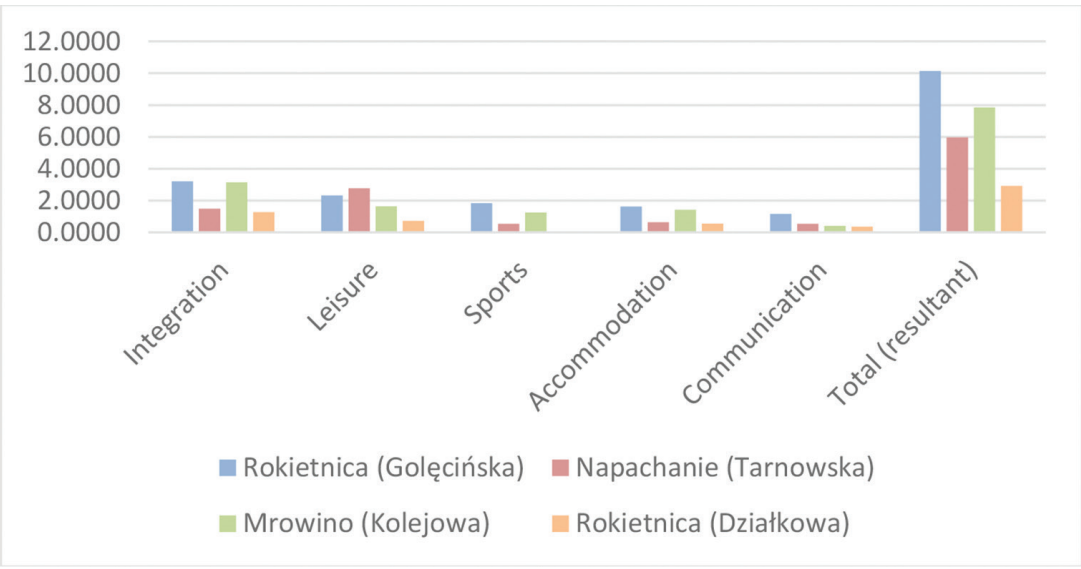

Figure 3: Comparative analysis of open public spaces in four different cases. Auth.: RB, 2018. 


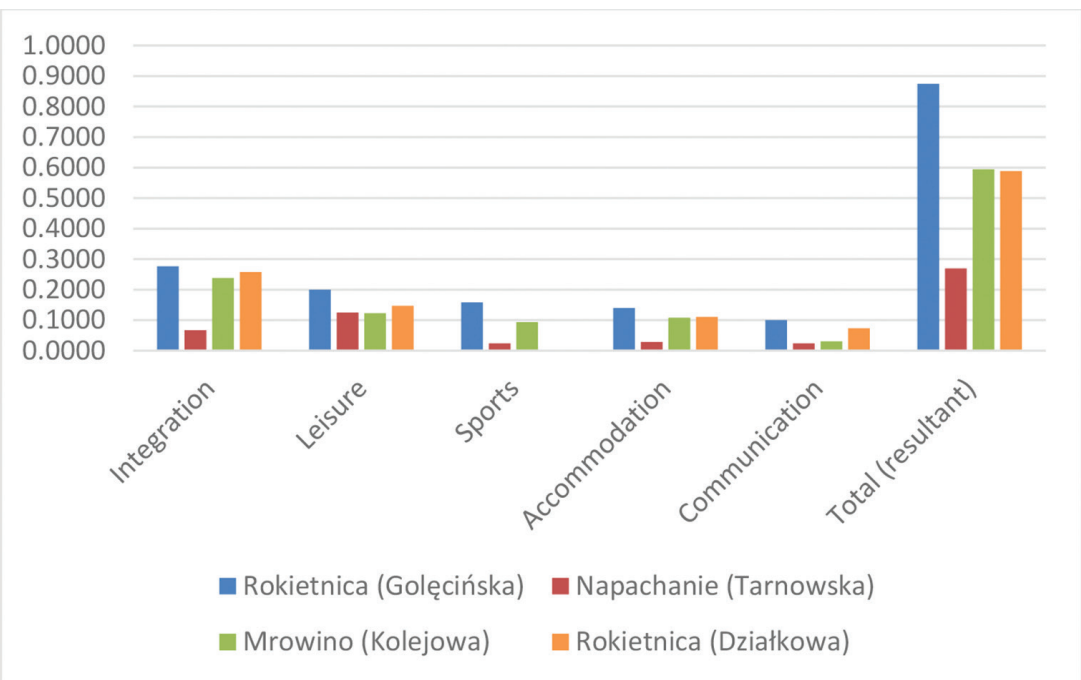

Figure 4: Comparative analysis of multi-functional efficiency of open public spaces in four different cases. Auth.: RB, 2018.

\section{DISCUSSION}

Data can be as helpful and improve our understanding related to spatial phenomena or misleading and treated routinely. In case of specific planning and designing problems in complex urban environment it is context that matters the most and ability to appropriately diagnose relationships and connect relevant pieces of information from data resources as well as from observation and inquiries or in-field examinations. All designers understand that open public spaces must conform to some requirements, yet often their design is derivative of multiple factors related to ownership structure, availability of space, and thus public domain is defined with significant share of random influences. These spaces are crafted, but rarely engineered.

Extended parametric analysis and establishing of connection between design effort and quality-typology (or value-based) pre-design imaging and assessment of potential of public spaces is one of possible ways to deal with some blind spots in urban design process. This aim-oriented approach has so far proven promising if not beneficial in establishing adjustments and improvements to projects presented in this paper. Its content stems from conviction that the development, to become or to be sustainable, must be constantly measured and verified to be better understood in every unique spatial setting.

\section{REFERENCES}

[1] Nijenhuis, W., City frontiers and their disappearance. Architectural Design Profile: The Periphery, 108, pp. 13-17, 1994.

[2] Barelkowski, R., The edge of the [dis]order. WIT Transactions on Ecology and The Environment, 155, pp. 759-770, 2012. 
[3] Schmidt, S. \& Németh, J., Space, place and the city: emerging research on public space design and planning. Journal of Urban Design, 15(4), pp. 453-457, 2010. https://doi.org/10.1080/13574809.2010.502331

[4] Searle, J., The Construction of Social Reality, The Free Press, New York, 1995.

[5] Madanipour, A., Why are the design and development of public spaces significant for cities? Environment and Planning B: Planning and Design, 26, pp. 879-891, 1999. https://doi.org/10.1068/b260879

[6] Benn, S.I. \& Gaus, G.F., The public and the private: concepts and action. Public and Private in Social Life, eds. S. Benn \& G. Gaus, Croom Helm, London, pp. 3-30, 1983.

[7] Lynch, K., The Image of the City, MIT Press, Cambridge, 1960.

[8] Mitchell, W.J., City of Bits: Space, Place, and the Infobahn, MIT Press, Cambridge, 1996.

[9] Cowley, R., Reframing the Problem of Public Space in the Sustainable City, RC21 International Conference on "The Ideal City: between myth and reality. Representations, Policies, Contradictions and Challenges for Tomorrow's Urban Life, Urbino, Italy, pp. 1-22, 2015.

[10] Mumford, L., The City in History. Its Origins, Its Transformations, and Its Prospects, A Harvest Book, Harcourt Inc., San Diego, 1989.

[11] Kostof, S., The City Shaped: Urban Patterns and Meanings Through History, Bulfinch, Boston, 1993.

[12] Memluk, M.Z., Designing urban squares. Advances in Landscape Architecture, ed. M. Özyavuz, InTech, pp. 513-530, 2013. https://doi.org/10.5772/55826

[13] Ilja, A.M., Does public space create social capital? International Journal of Sociology and Anthropology, 4(2), pp. 48-53, 2012. https://doi.org/10.5897/ijsa11.084

[14] Nissen, S., Urban transformation from public and private space to spaces of hybrid character. Sociologicky časopis/Czech Sociological Review, 44(6), pp. 1129-1149, 2008.

[15] Garcia-Domenech, S., Urban aesthetics and social function of actual public space: a desirable balance. Theoretical and Empirical Researches in Urban Management, 10(4), pp. 54-65, 2015.

[16] Matyjaszkiewicz, J. \& Putkowski, D., Zarys planowania przestrzennego, Wydawnictwa Szkolne i Pedagogiczne, Warszawa, pp. 144-149, 1971.

[17] Dabrowska-Milewska, G., Standardy urbanistyczne dla terenow mieszkaniowych wybrane zagadnienia. Architecturae et Artibus, 1/2010, pp. 17-31, 2010.

[18] Housing Quality Indicators, guidelines, latest version published May 17th, 2011, available at https://www.gov.uk/guidance/housing-quality-indicators, (accessed on March 10th, 2018). Also c.f. The National Affordable Homes Agency, 721 Housing Quality Indicators (HQI) Form, Ver. 4 (For NAHP 08-11), publ. May 2007, updated April 2008, containing tables with basic explanations.

[19] E.g. meeting particular factor of sqm/person instead of assessing whether these sqm are suitable to fulfill selected conditions - this is left for "expert" evaluation performed separately.

[20] Drucker, S.J. \& Gumpert, G., Public space and communication: the zoning of public interaction. Communication Theory, 1/4, pp. 294-310, 1991. https://doi.org/10.1111/j.1468-2885.1991.tb00022.x 
[21] Loukaitou-Sideris, A., Cracks in the city: addressing the constraints and potentials of urban design. Journal of Urban Design, 1(1), pp. 91-104, 1996. (Schmidt, S. \& Németh, J., Space, place and the city: emerging research on public space design and planning. Journal of Urban Design, 15(4), pp. 453-457, 2010).

https://doi.org/10.1080/13574809608724372

[22] Barelkowski, R., FAST Matrix: Depicting the Time-Related Aspect of Urban Development, in C. Brebbia and W. F. Flores-Escobar (eds.), The Sustainable City X, WIT Transactions on Ecology and The Environment, 194, pp. 3-10. See pp. 6-7.

[23] Rad, V.B. \& Ngah, I.B., The role of public spaces in promoting social interactions. International Journal of Current Engineering and Technology, 3(1), pp. 184-188, 2013. (See pp. 185 and 187).

https://doi.org/10.1111/issj.12064

[24] Soltanian, F. \& Mohammadi, A., Study of characteristics of urban public open spaces based on social interaction (Case study: Salavatabad's 3-kilometer route). European Online Journal of Natural and Social Sciences, 4(3), pp. 553-564, 2015. (See pp. 555-556).

https://doi.org/10.1016/b978-0-08-097086-8.03209-8

[25] Kim, S., Choi, J. \& Kim, Y., Determining the sidewalk pavement width by using pedestrian discomfort levels and movement characteristics. KSCE Journal of Civil Engineering, 15(5), pp. 883-889, 2011. (Although different, simpler method is used in analysed cases to determine the width of sidewalks, Kim et al. elaboration provides very good general reference on issues to be acknowledged.)

https://doi.org/10.1007/s12205-011-1173-1 